\title{
Quantifying Environmental Drivers of Future Tropical Forest Extent
}

\author{
Peter Good, Chris Jones, Jason Lowe, Richard Betts, And Ben Booth \\ Met Office Hadley Centre, Exeter, United Kingdom \\ CHRIS HUNTINGFORD \\ Centre for Ecology and Hydrology, Wallingford, United Kingdom
}

(Manuscript received 20 May 2010, in final form 30 September 2010)

\begin{abstract}
Future changes in atmospheric greenhouse gas concentrations, and their associated influences on climate, will affect the future sustainability of tropical forests. While dynamic global vegetation models (DGVMs) represent the processes by which climate and vegetation interact, there is limited quantitative understanding of how specific environmental drivers each affect the simulated patterns of vegetation behavior and the resultant tropical forest fraction. Here, an attempt is made to improve on the qualitative understanding of how changes in dry season length, temperature, and $\mathrm{CO}_{2}$ combine to drive forest changes. Investigation of these topics is undertaken by integrating the Hadley Centre Climate Model version 3, run at lower spatial resolution with a coupled climate-carbon cycle (HadCM3LC), to steady state. This represents the situation where vegetation has adjusted fully to the prevailing climate and vice versa, permitting direct analysis of how climate and vegetation interact. These links are quantified by fitting the simulated tropical broadleaf tree fraction with a simple function of $\mathrm{CO}_{2}$ concentration, surface temperature, and dry season length. The resulting empirical function (denoted dry season resilience or DSR) is able to predict a sustainable tropical broadleaf fraction in this model across a very wide range of climates. The DSR function can also be used to compare the importance of different environmental drivers and to explore other emissions scenarios. While this DSR function is specific to the vegetation-land surface scheme in HadCM3LC, the method employed in this work is applicable to steady-state simulations from other vegetation-land surface schemes.

The DSR metric is applied first as a framework to evaluate the DGVM by comparison of the simulated and observed forest fractions. For tropical broadleaf resilience in this model, a warming of $1{ }^{\circ} \mathrm{C}$ is approximately equivalent to a 2 -week increase in dry season. In HadCM3LC climate model projections under the International Panel on Climate Change's (IPCC's) Special Report on Emissions Scenarios (SRES) A1B scenario, twenty-first-century increases in forest resilience due to $\mathrm{CO}_{2}$ fertilization approximately balance the tropical mean decrease from warming (the relative importance of rainfall and temperature changes depends on the uncertain spatial pattern of rainfall change). DSR is a tool that could be applied to different vegetation models to help us understand and narrow uncertainty in tropical forest projections.
\end{abstract}

\section{Introduction}

One of the major environmental concerns associated with anthropogenic climate change is the potential for significant loss of tropical forests, most notably the Amazon rain forest. Dieback of the Amazon forest was first reported in simulations of a dynamic global vegetation model (DGVM) by White et al. (1999) and has subsequently been simulated by a coupled climate-carbon

Corresponding author address: Peter Good, Met Office Hadley Centre, Exeter EX1 3PB, United Kingdom.

E-mail: peter.good@metoffice.gov.uk cycle general circulation model (GCM), the Hadley center Climate Model version 3, run at lower spatial resolution with a coupled climate-carbon cycle (HadCM3LC; Cox et al. 2000; Cox et al. 2004). The phenomenon has since been found in simulations of both a range of vegetation models (Sitch et al. 2008) and for a range of different climate models (Scholze et al. 2006). Such dieback has been listed as a potential climate tipping point that may occur in the twenty-first century (Lenton et al. 2008) should emissions continue unabated. Betts et al. (2004) show that positive land-atmosphere feedbacks could amplify the overall loss of tropical rain forest. For many reasons, such a major change of terrestrial biomes is of obvious international concern. 
Currently, tropical forests play a vital role for sustaining unique and diverse ecologies, for their role in maintaining regional climate, and for the potential global feedback on climate through carbon storage. There is increasing emphasis on assessing tropical forest resilience within the scientific community. This includes model studies for Amazonia in particular (Salazar et al. 2007; Scholze et al. 2006) and also large-scale long-term observational campaigns in tropical forests across Amazonia (Phillips et al. 2009) and central Africa (Lewis et al. 2009). The 2005 Amazon drought showed that large-scale drying signals were not necessarily limited to the models (Cox et al. 2008; Marengo et al. 2008).

It has long been known that the large-scale distribution of biomes can be predicted from patterns of climate and, in particular, temperature and precipitation (Köppen 1936; Holdridge 1947). These "bioclimate models" have allowed for the calibration and application of schemes to predict changes in biome composition and terrestrial carbon storage under different climates. Early studies (e.g., Prentice and Fung 1990; Smith et al. 1992) were able to use such classification schemes to assess future changes in forest distributions under climate change scenarios from climate models with no representation of the vegetation processes. Smith and Shugart (1993) then extended the concept to apply transient rates of change to the classifications. Malhi et al. (2009) applied a similar approach to the Amazon, based on the annual mean and seasonal cycle of precipitation. However, none of these studies considered the direct impacts of changes in $\mathrm{CO}_{2}$ on vegetation. Crucifix et al. (2005) diagnosed the bioclimatic relationship between climate and vegetation in HadCM3LC for preindustrial and Last Glacial Maximum (LGM) conditions and found a significant role of changes in $\mathrm{CO}_{2}$, with decreased $\mathrm{CO}_{2}$ at LGM resulting in reduced vegetation amounts. Cowling et al. (2004) also analyzed past and future climate influences on tropical forests and the different balance between feedbacks involving stomatal conductance and leaf area in response to changing $\mathrm{CO}_{2}$ levels.

Projections of future forest stability now make use of more sophisticated coupled numerical modeling of the earth system. GCMs represent the most sophisticated tools for projections of the future climate response to changes in atmospheric greenhouse gas and aerosol composition and land surface properties. DGVMs represent the processes that determine the growth and carbon storage of discrete plant functional types, the competition between them, and the time scales of their response (Cramer et al. 2001). Coupled climate-vegetation simulations allow representation of both future changes in vegetation in response to climate change (e.g., Jones et al. 2009) and also the impacts of changes in land surface on climate (e.g., Betts et al.
2004). In these simulations, $\mathrm{CO}_{2}$, rainfall, and temperature all affect the modeled vegetation distribution, although the magnitudes of their effects are uncertain (e.g., Lapola et al. 2009; Galbraith et al. 2010, manuscript submitted to Global Biogeochem. Cycles, hereafter GLSHWM). Our study aims to quantify their effects for the vegetation-land surface scheme within the HadCM3LC climate model.

Increased $\mathrm{CO}_{2}$ affects vegetation in two ways. The higher ambient $\mathrm{CO}_{2}$ levels directly enable more carbon uptake by plants [the $\mathrm{CO}_{2}$ fertilization effect; Norby et al. (2005)]. Plants also respond by narrowing their stomata (Field et al. 2008), reducing leaf water loss, and hence increasing wateruse efficiency.

The Amazon forest loss in the simulations by Cox et al. (2000) coincides with a large-scale drying signal driven by changes in the Atlantic and Pacific (Harris et al. 2008; Good et al. 2008), and this has been postulated to be the main driver of the Amazon dieback (Cox et al. 2004). Current GCMs show large differences in projections of future rainfall changes over most land locations (Meehl et al. 2007), including over the Amazon (Malhi et al. 2009).

Temperature changes also affect the simulated plant development both directly, through the temperature sensitivities of photosynthesis and respiration, and indirectly by affecting water evaporation rates (GLSHWM). A significant role for temperature as a driver of Amazon forest lost was suggested by Salazar et al. (2007) and GLSHWM. GLSHWM provide a detailed investigation of the mechanisms of Amazon forest loss in three different DGVMs forced by climate projections from one climate model.

Efforts to quantify and reduce uncertainty regarding future change in tropical forest still require improved quantitative understanding of how climate and $\mathrm{CO}_{2}$ control the forest amount. Such quantitative understanding could help validate and intercompare different models, estimate the sensitivity of forest projections to climate model errors, or to predict-he forest amount for other emissions scenarios for which the complex climate models have not been run.

Here, we extend the concept of two-dimensional (temperature and rainfall) bioclimatic zones to include a third component $\left(\mathrm{CO}_{2}\right)$, and we apply it to future projections, making it more policy relevant. We study simulations of a "sustainable broadleaf forest fraction," which we define as the eventual forest fraction simulated when the vegetation is allowed to adjust fully to the prevailing climate [which may be significantly different from the dynamical forest fraction in full time-dependent simulations; see Jones et al. (2009). This eliminates the lagged forest response to climate and, so, allows direct links to be made between the forest fraction and environmental drivers. 
TABLE 1. Summary data on the "equilibrium" mode model integrations.

\begin{tabular}{lccr}
\hline $\begin{array}{c}\text { Model } \\
\text { simulation name }\end{array}$ & $\begin{array}{c}\text { Year of } \\
\text { initialization }\end{array}$ & $\begin{array}{c}\mathrm{CO}_{2} \text { (ppmv) seen by } \\
\text { the vegetation scheme }\end{array}$ & $\begin{array}{c}\text { Tropical mean } \\
\text { land temp }\left({ }^{\circ} \mathrm{C}\right)\end{array}$ \\
\hline $2005 \mathrm{~s}$ & 2005 & 390 (same as climate model) & 25.2 \\
$2060 \mathrm{~s}$ & 2060 & 636 (same as climate model) & 28.5 \\
$2080 \mathrm{~s}$ & 2080 & 801 (same as climate model) & 29.7 \\
$2100 \mathrm{~s}$ & 2100 & 1027 (same as climate model) & 31.3 \\
$2100 \mathrm{~s}-\mathrm{lowVegCO} \mathrm{C}_{2}$ & 2100 & 379 (as year 2000 climate) & 31.2 \\
\hline
\end{tabular}

\section{Data and methods}

We first describe the model simulations formulated to allow direct analysis of the links between climate and vegetation. We then fit an empirical function to the results to quantify the importance of specific environmental drivers. We quantify the main environmental drivers of the sustainable tropical broadleaf forest fraction simulated by the Met Office Surface Exchange Scheme-Top-down Representation of Interactive Foliage and Flora Including Dynamics (MOSES-TRIFFID) DGVM within the HadCM3LC climate model. We then apply this to advance our understanding of the HadCM3LC simulations.

HadCM3LC was one of the coupled carbon cycle GCMs used in the Coupled Climate-Carbon Cycle Model Intercomparison Project ( $\mathrm{C}^{4} \mathrm{MIP}$; Friedlingstein et al. 2006) and includes MOSES2, the land surface model (Essery et al. 2003), coupled to a dynamic vegetation component, TRIFFID (Cox 2001). HadCM3LC has a spatial resolution of $2.5^{\circ}$ latitude $\times 3.75^{\circ}$ longitude. MOSES2 has a fourlayer soil model with a total soil depth of $3 \mathrm{~m}$. TRIFFID represents 5 plant functional types (PFTs): broadleaf trees, needleleaf trees, shrubs, and C3 and C4 grasses. This represents a substantial simplification compared to the large range of species in the real world, including both evergreen and dry deciduous broadleaf in the tropics. The regional extent of these vegetation types is determined by the net primary productivity of each PFT and competition between them. The Lotka-Volterra equations in TRIFFID are known to overestimate (underestimate) the fractional coverage of the dominant (subdominant) plant functional type (Arora and Boer 2006). The vegetation responds to a wide array of environmental drivers, such as moisture availability, light, temperature, and carbon dioxide fertilization. The dependence of plant growth on nutrients (Thornton et al. 2009) or direct and diffuse light (Mercado et al. 2009), and the effects of fire (Malhi et al. 2009) or other disturbances, are likely to be important but are not yet represented in this model.

To explore the relationships between forest cover and temperature, dry season length and $\mathrm{CO}_{2}$ fertilization, we make use of two configurations of HadCM3LC. In its standard configuration, HadCM3LC simulates the timeevolving forest extent, in response to changes in climate variables and simulated vegetation productivity. This configuration is used to simulate the climate response for the years 1860-2100, using the $\mathrm{CO}_{2}$ emission component of the Special Report on Emissions Scenarios (SRES) A2 scenario (Nakicenovic et al. 2000) for the future period.

A second configuration involves using the land surface scheme in "equilibrium" mode [see Cox (2001) and the supplementary information in Jones et al. (2009) for details]. This mode allows the forest to fully adjust to the prevailing climate (effectively by running the vegetation scheme for extra time steps, decoupled from the climate model). This simulates the "sustainable forest fraction." We make use of four such simulations. Each of these simulations was initialized from a different part of the "transient" simulation, to quantify equilibrium forest responses to the climate state in 2005, 2060, 2080, and 2100 (simulations denoted 2005s, 2060s, 2080s, and 2100s; see Table 1). For each simulation we present the temperature and dry season length averaged over the whole simulation, and the broadleaf forest fraction at the end of the simulation.

We also use observationally based data. An estimate of tropical tree cover is included based on translation of the International Geosphere-Biosphere Programme (IGBPDIScover) land cover classification (Loveland and Belward 1997) into the TRIFFID plant functional types (see appendix A). Monthly gridded observations of surface temperature and precipitation are taken from the Climate Research Unit (CRU) version 2.1 dataset (Mitchell and Jones 2005), and averaged over 1950-2002. A current observed $\mathrm{CO}_{2}$ concentration of $390 \mathrm{ppm}$ is used (Keeling et al. 2009).

We quantify the dependence of forest fraction on three key environmental drivers of forest fraction via three indices. These indices are chosen as the simplest relevant measures of $\mathrm{CO}_{2}$, temperature, and dry season effects. The $\mathrm{CO}_{2}$ concentration is a global scalar, while temperature and dry season indices are quantified at each grid location. For the first two, we use $\mathrm{CO}_{2}$ concentration and local annual mean temperature. We estimate the length of the dry 
season as the number of months in a given year where the monthly rainfall is less than $100 \mathrm{~mm}$. This represents the period where vegetation is water stressed. The threshold is somewhat arbitrary and was chosen to be equivalent to the estimate of the canopy evaporation rate used by Malhi et al. (2009). Malhi et al. (2009) used a slightly more complex measure of dry season intensity, accounting for the precipitation rate during the dry season. Our choice of dry season length as a metric was motivated by a criterion of minimal sensitivity to model or measurement uncertainty. We argue that it is likely to be challenging for both climate models and observational methods to represent accurately the low rainfall rates during the dry season. That is, it is easier to quantify the length of the dry season than to quantify a measure depending on both the dry season length and the rainfall rate during the dry season. Therefore, we test first whether the dry season length is sufficient for our purposes. We tested the sensitivity to the dry season threshold by repeating the test of the method skill (Fig. 3a below) for thresholds of $50 \mathrm{~mm} \mathrm{month}^{-1}$ and $150 \mathrm{~mm} \mathrm{month}{ }^{-1}$. The results were essentially unchanged.

We confine our analyses of forest-environmental relationships to tropical land from $20^{\circ} \mathrm{S}$ to $20^{\circ} \mathrm{N}$, where broadleaf is the dominant forest type. Our results would not necessarily be expected to be applicable outside this region.

\section{Model simulations of climate and sustainable broadleaf fraction}

Here, we introduce the model results, and discuss links between environmental drivers and sustainable broadleaf forest fraction. For simplicity, we present a picture of the climate and $\mathrm{CO}_{2}$ driving forest fraction. The influence of forest fraction on the regional climate is addressed later. The distributions of tropical broadleaf, dry season length, and temperature in the 2005s simulation are shown in Fig. 1 (left column). To a first approximation, the major tropical forests in South America, Africa, and the Maritime Continent correspond to the regions with short dry seasons (Fig. 1). Little forest is simulated where the dry season is 8 months or longer. A link between forest cover and dry season length using real-world observations was previously reported by ter Steege et al. (2006). In contrast, the spatial pattern of the tropical forest bears little relation to the pattern of the surface air temperature. The spatial correlation between the broadleaf fraction and dry season length (temperature) is $-0.8(-0.1)$. Of these two potential environmental drivers, dry season length appears to play a larger role in determining the present-day forest distribution. HadCM3LC has broadly realistic spatial patterns of broadleaf fraction, dry season length, and temperature compared with the observations (not shown), although our analysis is insensitive to the particular spatial patterns of climate simulated by the model.

In the 2100s simulation (Fig. 1, right column), the model has simulated the loss of much of the Amazon rain forest, although there is minimal forest change elsewhere. It is worth noting that this does not represent the projected forest fraction for 2100, but the longer-term sustainable fraction after full adjustment to the 2100 climate (Jones et al. 2009). As such, it is not expected to depend strongly on the transient scenario of how this climate state arose. Similarly, the dry season length shows a large increase over much of the Amazon, and minimal change elsewhere. This again implicates dry season length as one key driver of forest fraction. There is substantial model uncertainty in the spatial patterns of the future climate change, especially for precipitation (e.g., Malhi et al. 2009). However, our main result in section 4 below (that the presence of forest in this model is predicted by a simple function of three environmental drivers) is largely independent of the spatial patterns of climate change simulated by HadCM3LC.

To measure the importance of $\mathrm{CO}_{2}$ fertilization, we repeated the 2100s simulation, but with the $\mathrm{CO}_{2}$ concentration seen by the vegetation scheme set to present-day levels. In this simulation (denoted 2100s-LowVegCO2), almost all of the tropical forest is lost (Fig. 1, right column, 2100s-LowVegCO2). This has two implications. First, that $\mathrm{CO}_{2}$ concentration plays an important role in forest resilience in this model. That is, climate change driven by non$\mathrm{CO}_{2}$ greenhouse gases is significantly more detrimental for tropical forests according to this model (although the absence of observed evidence of how tropical species behave under increased $\mathrm{CO}_{2}$ is an important research gap). The loss of forest outside of the Amazon also suggests an important environmental driver other than dry season length. The most obvious candidate is surface temperature. In this projection, surface warming is likely to be most important over the Amazon, where temperatures reach $36^{\circ} \mathrm{C}$ by 2100 . All this illustrates that forest depends on these environmental drivers within this model. We now go a step further and quantify the relative importance of each.

\section{Quantifying the climate controls on sustainable broadleaf fraction}

The links between forest cover and climate are shown more directly for the 2005s model simulation in Fig. 2a. This shows results from all tropical land locations: each cross represents one tropical land grid cell. The position of each cross shows the climate conditions (dry season length and temperature), and the color shows the broadleaf forest fraction in the same grid cell. The locations with high and low broadleaf cover amounts separate clearly into two bioclimatic zones. The zones of high (low) cover are to first 


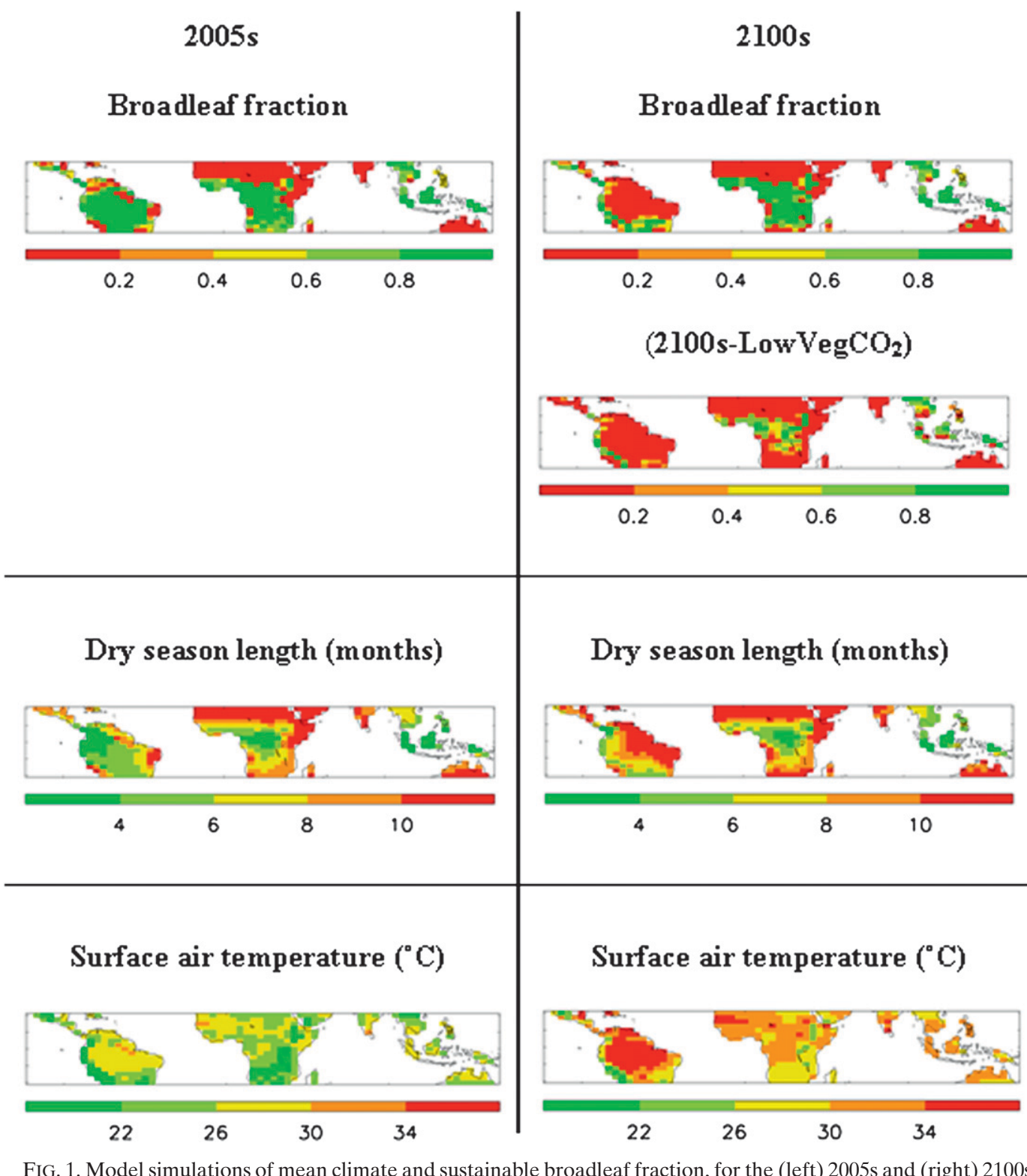

FIG. 1. Model simulations of mean climate and sustainable broadleaf fraction, for the (left) 2005s and (right) 2100s simulations. Also, shown is the broadleaf fraction from the 2100 s-lowVegCO2 run (right column, second from top). The climate for the 2100s-lowVegCO2 run (not shown) is very similar to the 2100s run.

order those with short (long) dry seasons. The role of temperature and the precise zone boundary are unclear based on data from this simulation alone.

Similar bioclimatic zones occur for the 2100s simulation (Fig. 2b), but in this simulation, the relationship between the temperature and broadleaf fraction is clearer. For dry season lengths of 7-10 months, high (low) forest cover is found at locations with low (high) temperatures. This clearer signal emerges because there is a larger range of temperatures in the 2100s simulation-partly because twenty-first-century warming is much larger in the central Amazon than elsewhere in the tropics. The boundary between the zones of high and low forest is also found at a different location for the 2100s simulation than for the 2005s simulation (cf. Figs. 2a and 2b). This precludes a definition for the zone boundary based solely on temperature and dry season length.

The two zones emerge again in the 2100s-lowVegCO2 simulation (Fig. 2c). The impact of reduced $\mathrm{CO}_{2}$ fertilization in this simulation is clear (cf. Figs. $2 b$ and 2c): tropical broadleaf is sustainable only at locations with the shortest dry seasons. This time the zone boundary is very similar to that in the $2005 \mathrm{~s}$ simulation, which had an almost identical $\mathrm{CO}_{2}$ concentration (cf. Figs. $2 \mathrm{c}$ and 2a). 


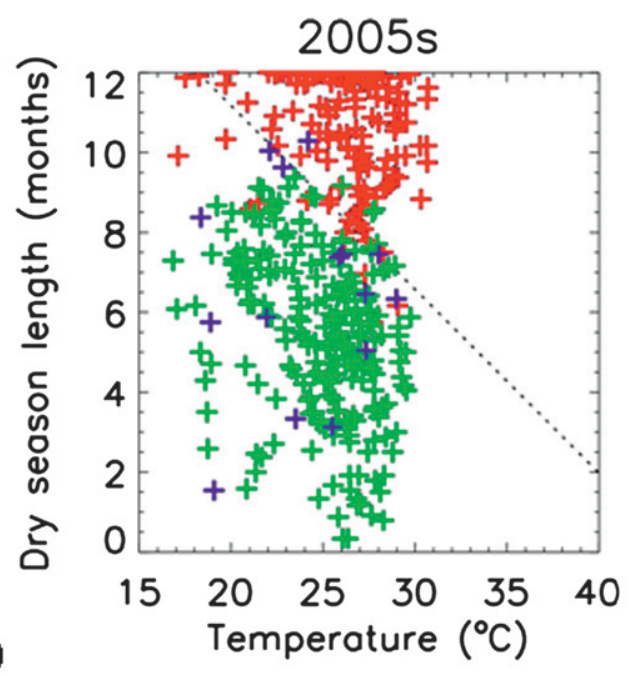

a)

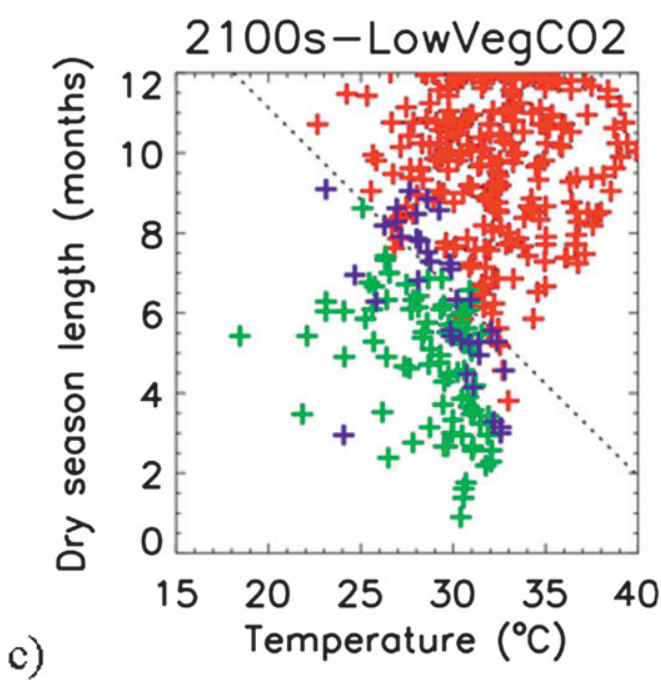

In other words, by including $\mathrm{CO}_{2}$ in our analysis, we can define bioclimatic zones that appear to be robust to both changes in climate and $\mathrm{CO}_{2}$ concentration. Given that dry season length, temperature, and $\mathrm{CO}_{2}$ concentration appear to explain much of the spatiotemporal variation in the broadleaf fraction in these simulations, we now quantify their links to tropical forest resilience within this model.

\section{Dry season resilience}

To quantify the two bioclimatic zones, we derive a linear function of dry season length, temperature, and $\mathrm{CO}_{2}$ concentration, which we denote dry season resilience (DSR). While the general relationship between vegetation and environment is nonlinear, we test whether a linear function is a useful approximation over the range of conditions in our GCM experiments.

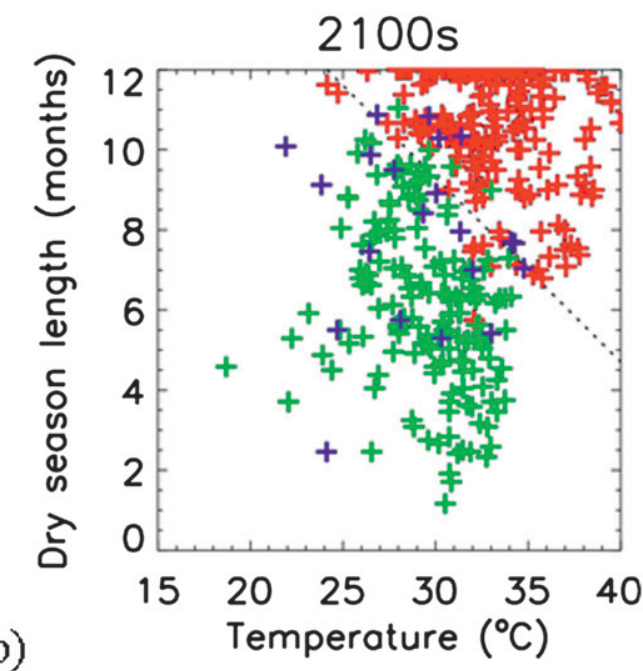

FIG. 2. Simulated bioclimatic zones of tropical broadleaf fraction. Each panel shows the broadleaf fraction (symbol color) as a function of dry season length ( $y$ axis) and surface temperature ( $x$ axis), for all tropical land grid cells in one model simulation. Each cross represents the conditions for 1 tropical land grid cell. Red crosses indicate the broadleaf fraction is $<0.05$, blue is for $0.05-0.4$, and green is for $>0.4$. Dotted lines show the contours of DSR (defined in section 4) $=0$, for (a) 2005s, (b) 2100s, and (c) 2100s-lowVegCO2.
For any environmental conditions (of dry season length, temperature, or $\mathrm{CO}_{2}$ concentration), DSR predicts which of the two bioclimatic zones these conditions reside in (i.e., whether high or low forest fraction is sustainable). Large positive (negative) values indicate that high (low) forest fraction is sustainable at equilibrium. Further, DSR predicts how far these environmental conditions are from the boundary between the 2 zones (the boundary is given by DSR $=0$; the dotted line in Fig. 2).

We test the simplest possible formulation for DSR, a linear function:

$$
\text { DSR }=(\text { dry season length })+\alpha_{T} T+\alpha_{\mathrm{CO}_{2}} \mathrm{CO}_{2}+c,
$$

where $\alpha_{T}, \alpha_{\mathrm{CO} 2}$, and $c$ are constants with units of: months $\left({ }^{\circ} \mathrm{C}\right)^{-1}$, months $(\mathrm{ppmv})^{-1}$, and months, respectively. Dry 

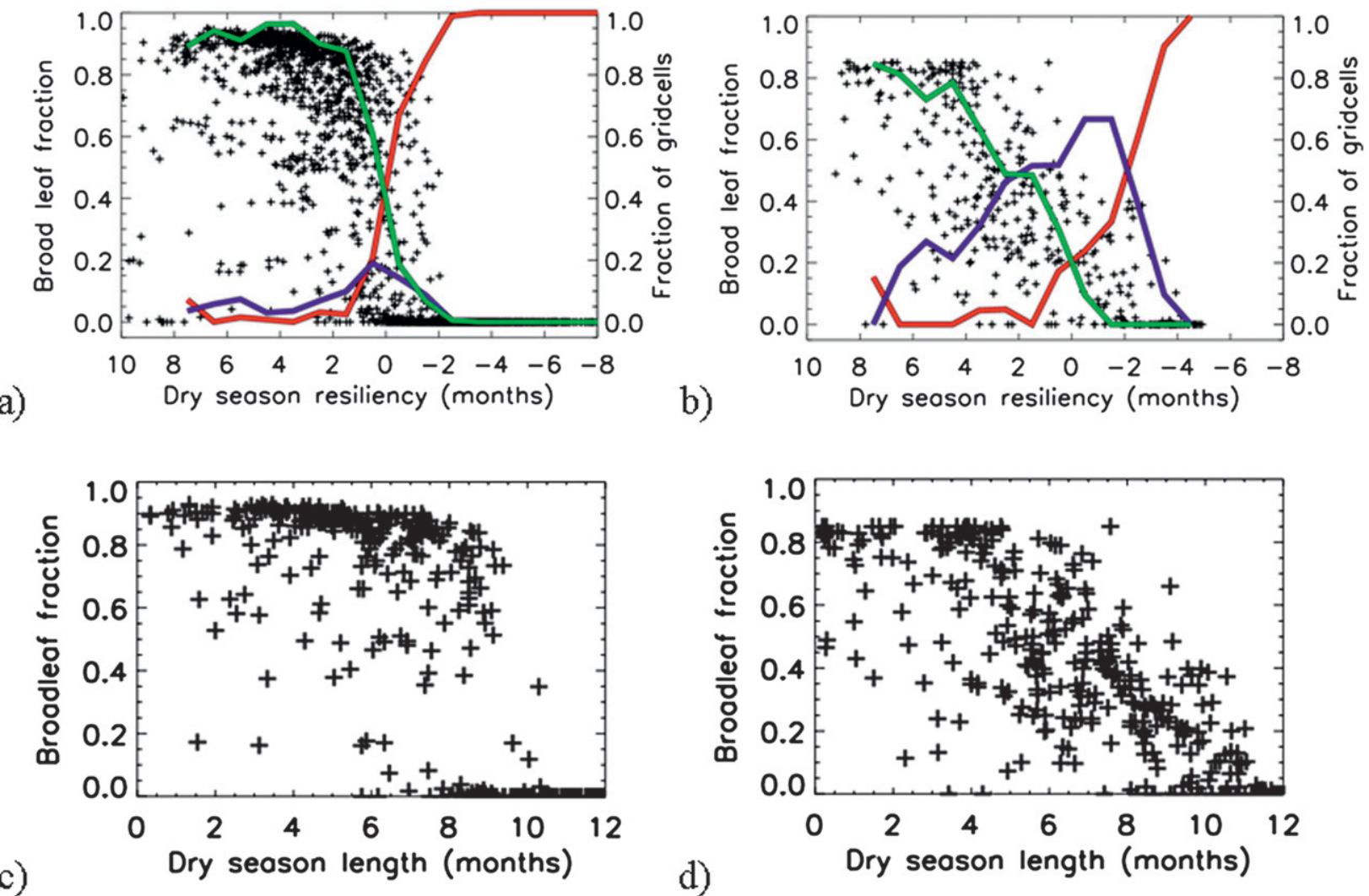

FIG. 3. The relationship between broadleaf fraction and dry season resilience. (a) Data from HadCM3LC, including that from all 5 simulations. Each cross shows 1 grid cell from 1 model simulation. Red line indicates the proportion of grid cells with broadleaf fraction $<0.05$, blue the proportion of grid cells with $0.05 \geq$ broadleaf fraction $>0.4$, and green the proportion of grid cells with broadleaf fraction $\geq 0.4$. (b) As in (a), but using the observed broadleaf fraction, temperature, rainfall, and $\mathrm{CO}_{2}$. Broadleaf fraction against dry season length for (c) the $2005 \mathrm{~s}$ model simulation and (d) the observations.

season length (months), $T\left({ }^{\circ} \mathrm{C}\right)$, and $\mathrm{CO}_{2}$ concentration (ppmv) are the environmental drivers. DSR has units of months [due to the form of Eq. (1)]. It can be thought of as being the maximum increase in the length of the dry season a tropical forest could survive if the temperature and $\mathrm{CO}_{2}$ concentration are unchanged. The equivalent critical changes in temperature and $\mathrm{CO}_{2}$ can also be inferred. The $\alpha_{T}$ and $\alpha_{\mathrm{CO} 2}$ are relative measures of the importance of changes in temperature and $\mathrm{CO}_{2}$ compared to a 1-month change in dry season length.

We derive values for the constants by an empirical fit to HadCM3LC model data (i.e., simulated values of broadleaf fraction, temperature, dry season length, and $\mathrm{CO}_{2}$ concentration). This function is fitted using the combined dataset of model results from all tropical land locations in all five simulations. The dataset represents a wide range of different climate states projected by HadCM3 (spanning temperatures from $17^{\circ}$ to $40^{\circ} \mathrm{C}$, dry season lengths from 0.4 to 12 months, and $\mathrm{CO}_{2}$ concentrations from 390 to $1027 \mathrm{ppmv}$ ). The fitting method (detailed in appendix B) is chosen so that DSR $=0$ marks the boundary between the bioclimatic zones of higher and lower forest fractions. The resulting function is

$$
\begin{aligned}
\mathrm{DSR}= & (\text { dry season length })+0.46 T \\
& -0.0043 \mathrm{CO}_{2}-18.7 .
\end{aligned}
$$

The ability of the DSR function to describe HadCM3LC broadleaf is illustrated first in Fig. 2, where the dotted lines show isolines of DSR $=0$. A more detailed assessment is given in Fig. 3a. This plots broadleaf fraction against DSR for each tropical land point in each of the five model simulations, showing that the DSR function is quite successful at describing the resilience of tropical broadleaf in HadCM3LC. Since the data are not normally distributed, standard measures like correlation coefficient are not appropriate, so we quantify the performance as follows. Climates in low and high resilience are well distinguished: in regions with DSR less than -1.5 months, at least $85 \%$ of cells have a broadleaf fraction of less than 0.05 (red line in Fig. 3a), and under 6\% have a broadleaf fraction greater than 0.4 (green line). Where DSR is greater 
than 1.5 months, at least $85 \%$ of cells have a broadleaf fraction greater than 0.4 and under $10 \%$ of cells have a broadleaf fraction of less than 0.05 . Further, DSR has some ability in identifying locations with intermediate resilience: for $-1.5 \leq \mathrm{DSR} \leq 1.5$, the proportion of cells with broadleaf fractions between 0.05 and 0.4 (blue line) is clearly elevated. In other words, the transition region with values of DSR close to zero has distinct physical meaning and is not simply a region where forest cover is unpredictable. The scatter in the relationship between DSR and broadleaf fraction is due to additional factors not included in the DSR equation, such as details of the local temperature or precipitation seasonal cycles or incoming radiation (e.g., Nemani et al. 2003).

The results above express close statistical links between forest fraction and three quantities referred to as environmental drivers. These statistical links do not inherently show that the climate is driving the forest fraction and not vice versa. It is theoretically possible for example that the link to dry season length could have been caused by the forest fraction controlling the regional rainfall climate. Betts et al. (2004) showed that simulated forest loss can suppress local evaporative water recycling and hence reduce rainfall. However, the variations of $\mathrm{CO}_{2}$ and temperature across our 5 e experiments are dominated by factors other than variations in local forest fraction. We note that $\mathrm{CO}_{2}$ is well-mixed globally and variations between the different experiments are dominated by anthropogenic emissions. Similarly, spatial patterns in temperature do not resemble those in forest fraction, and the variation between the different experiments is due to radiative forcing by $\mathrm{CO}_{2}$. For the case of dry season length, it is also the case that the large spatial variations in dry season length are driven by large-scale atmospheric circulation and moisture transport rather than by the presence (or absence) of forest. As a further check, we estimate the influence of forest fraction on dry season length by comparing the results from the two experiments with 2100s climate (2100s and 2100slowVegCO2). In the 2100s-lowVegCO2 experiment, forest dieback is caused artificially by forcing the vegetation to experience year-2000 ambient levels of $\mathrm{CO}_{2}$. We find in this model that loss of tropical forest causes an increase in the dry season length of around 0.5 months (see appendix C). This is small compared to the spatial variation of dry season length due to external forcing (Fig. 2). It strongly implies that the links between the three environmental drivers and broadleaf fraction are to first order determined by the influence of the climate on the vegetation. In other words, we do not expect vegetation feedbacks on climate to affect the DSR function quantifying the location of the boundary between the bioclimatic zones of high-low forest. However, this may not be true for all regions or across different climate models. Quantifying the strength and implications of such biophysical feedbacks remains an important research question.

\section{Validation}

We can investigate the relevance of this approach beyond the scope of this model by considering the DSR implied by observational data. An initial observational validation is shown in Fig. 3b. This uses the model-derived DSR function [Eq. (2)], but applied to observed values of broadleaf fraction, $\mathrm{CO}_{2}$ concentration, temperature, and dry season length. The DSR is able to identify observational regions of low and high broadleaf cover solely on the basis of the environmental drivers.

Such an observational validation has fundamental limitations. First, we cannot observe the sustainable (equilibrium) forest fraction. The observable forest fraction is a result of time-evolving past climate, and is disturbed by direct human influence (e.g., deforestation). Also, the variation in DSR is dominated by spatial variation in dry season length (as in HadCM3LC; see Figs. 2a, 3c, and 3d). This means that Fig. $3 b$ primarily confirms the link between dry season length and present-day forest cover previously observed over Amazonia (ter Steege et al. 2006). The spatial variations in temperature and $\mathrm{CO}_{2}$ concentration are too small to affect Fig. 3b. Paleo-reconstructions of regional climate and tropical forest cover are not sufficiently accurate to allow the derivation of observed DSR under past climates and so the $\mathrm{CO}_{2}$ coefficient of Eq. (1) remains impossible to constrain through observations. Better understanding of the long-term response of vegetation (and especially tropical vegetation) to changes in $\mathrm{CO}_{2}$ concentration is urgently required.

Figure 3b does however show that HadCM3LC (Fig. 3a) captures the broad distribution of tropical broadleaf. Given the above limitations, we focus on a coarse-scale view represented by the red, blue, and green lines in Fig. 3. In both the model (Fig. 3a) and observations (Fig. 3b), the fraction of grid cells with very low forest cover (red lines) is small where the dry season resiliency is larger than 1.5 months. Both the model and observations also have very few grid cells with high forest cover (green lines) where the dry season resiliency is less than -1.5 months.

The main issue with the model appears to be that it has too few locations with intermediate forest cover (blue lines). This is probably because the Lotka-Volterra approach used by TRIFFID overestimates (underestimates) the fractional coverage of the dominant (subdominant) plant functional type (Arora and Boer 2006). Also, the model lacks fire disturbances, leading to too much forest cover in disturbance-dominated savanna regions. This model bias does make it easier to demonstrate that DSR is a good description of this land surface scheme (Fig. 3a). 
We expect that our method would be applicable to models with more realistic vegetation distributions, but this needs testing using appropriate equilibrium vegetation simulations.

\section{Discussion and conclusions}

We can capture the key relationships of environmental drivers with tropical forest cover using a simple statistical relationship with three environmental indices. We have shown that the sustainable broadleaf fraction simulated by the MOSES-TRIFFID DGVM within the HadCM3LC climate model is well predicted by an empirical linear function of local dry season length, temperature, and $\mathrm{CO}_{2}$ concentration (denoted dry season resilience or DSR). This function describes the MOSES-TRIFFID vegetation-land surface scheme. It is derived using spatiotemporal patterns of climate and vegetation covering the entire tropics, and is largely independent of the spatial patterns of climate change simulated by HadCM3LC. DSR can be thought of as the maximum increase in the length of the dry season a tropical forest could survive if temperature and $\mathrm{CO}_{2}$ concentration are unchanged. There is some scatter in the relationship between DSR and broadleaf fraction, so DSR is best suited for exploring the large-scale response of the tropical forest, rather than providing useful insights on an individual grid-box scale. We do not recommend applying DSR outside the range of climate states explored in this study.

A key part of this work was to use the DGVM in equilibrium mode. Our results refer to the forest fraction remaining after full adjustment to the prevailing climate. This allowed us to relate the sustainable forest fraction directly to environmental drivers. Thus, the DSR function would not be appropriate with full time-dependent simulations, where tropical forest fraction has a lagged response to climate change [of the order of $100 \mathrm{yr}$; see Jones et al. (2009)].

It would be useful to test different formulations of DSR, perhaps based on different environmental drivers [e.g., the maximum water moisture deficit proposed by Malhi et al. (2009)] or additional drivers [such as cloud cover; Nemani et al. (2003)], or to test nonlinear functions of these drivers. However, we did test a version of DSR using a logarithmic function of $\mathrm{CO}_{2}$ concentration, and the performance (as in Fig. 3a) was almost identical to the full linear DSR reported above. Also, our results suggest that the linear DSR function is useful for explaining the major variations of forest resilience in a very wide range of climates. We judge that in future work it would be more important first to explore DGVM uncertainty, which is large (GLSHWM) rather than trying more refined formulations of DSR for the present
DGVM. DGVMs within existing climate models have also been found to have a poor representation of presentday seasonal cycle in tropical forest productivity (Baker et al. 2008; Saleska et al. 2007). The validity of DSR for climate states outside those explored here should also be investigated (e.g., at higher temperature- $\mathrm{CO}_{2}$ concentrations, or in projections from different climate models or for paleoconditions). However, our experiments did explore a very large range of climate states, suggesting quite general applicability.

There are various potential applications of the DSR function in quantifying and reducing the uncertainty in tropical forest projections. For example, the relative strengths of the three environmental drivers in the HadCM3LC model can be inferred from the coefficients in Eq. (2). In terms of tropical forest resilience, a local warming of $1^{\circ} \mathrm{C}$ is equivalent to about half a month's worth of increase in local dry season length. Similarly, a $\mathrm{CO}_{2}$ increase of $500 \mathrm{ppm}$ is approximately equivalent to a 2-month decrease in local dry season length or a $5^{\circ} \mathrm{C}$ decrease in local temperature. That is, if a particular location happened to experience a $\mathrm{CO}_{2}$ increase of $500 \mathrm{ppm}$ accompanied by a $5^{\circ} \mathrm{C}$ warming and no change in dry season length, we would expect the tropical forest to be largely unaffected in this model. This has implications for the effects of different greenhouse gas emissions scenarios and multi-gas mitigation policy: an equivalent warming by non- $\mathrm{CO}_{2}$ greenhouse gases would have a much larger impact on tropical forests, because this warming would not be balanced by forest fertilization. In addition to its radiative forcing, the detrimental effects of $\mathrm{CO}_{2}$ on ocean ecosystems through acidification have been well documented (e.g., Orr et al. 2005). But the direct (and possibly beneficial) physiological effects on terrestrial ecosystems must also be considered.

The previous statements apply to any tropical location. We now use spatial climate patterns to draw some location-specific conclusions. Using observed temperature, dry season length, and $\mathrm{CO}_{2}$, we can illustrate the presentday distribution of dry season resilience, as shown in Fig. 4, based on observed values of dry season length, temperature, and $\mathrm{CO}_{2}$ concentration, as well as the model-derived DSR function. This indicates the magnitude of climate change different regions could experience while maintaining extensive forest cover (negative values indicate that high forest cover is likely to be unsustainable in the present climate). This map is based on observed climate data and, so, makes no assumptions about the future changes in climate. This kind of information could form one component of a risk analysis framework, for example by identifying regions that may have crossed, or are about to cross, a threshold and become committed to forest loss before any such loss is observable. 


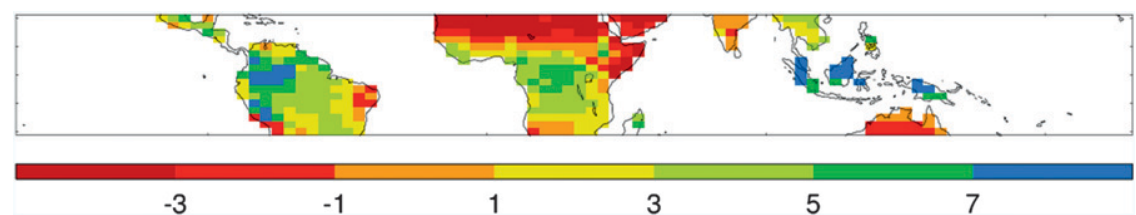

FIG. 4. Present-day DSR (calculated using observed temperature, dry season length, and $\mathrm{CO}_{2}$ concentration).

We also applied the DSR function to a preliminary analysis of the HadCM3LC projections under the SRES A2 emissions scenario. The changes between the 2005s and 2100s simulations in $\mathrm{CO}_{2}$ and tropical mean land temperature are $637 \mathrm{ppm}$ and $6.1^{\circ} \mathrm{C}$, respectively. Therefore, from Eq. (1), the tropical mean change in DSR due to warming $=\alpha_{T} \times 6.1=2.8$ months. The $\mathrm{CO}_{2}$ effect $=\alpha_{\mathrm{CO} 2} \times 637=2.7$ months. That is, in this model the twenty-first-century tropical mean changes in DSR due to warming and $\mathrm{CO}_{2}$ fertilization approximately balance. This is why the forest extent changes little outside the Amazon (as dry season length changes are mostly small outside the Amazon). Over the Amazon, warming and dry season length changes are both somewhat larger than the tropical mean (see Fig. 1). In other climate model projections, forest resilience may be quite sensitive to differences in the rate of warming per unit $\mathrm{CO}_{2}$ rise, or in the regional patterns of precipitation change.

In conclusion, the DSR function provides a good, straightforward quantitative description of how three major environmental drivers control tropical forest extent in MOSES-TRIFFID. Potential applications include identifying which environmental drivers are dominant in the various state-of-the-art earth system models and understanding which aspects of climate change uncertainty (e.g., temperature or rainfall changes) the forest is most sensitive to. Identifying the role of each of these environmental drivers for a given modeling framework also enables estimates of sustainable forest cover to be estimated for alternative scenarios for which the DGVM model was not used. Our empirical relationship describes a single DGVM. This technique will be useful for characterizing forest-environmental driver relationships within different DVGMs. This would provide us with a very simple metric of forest resilience, which is both readily intuitive to understand and summarizes in a concise way the major differences that exist between models.

Acknowledgments. This work was supported by the Joint DECC/Defra Met Office Hadley Centre Climate Programme (GA01101). We acknowledge insightful comments from three reviewers, which improved the manuscript significantly.

\section{APPENDIX A}

\section{Estimation of the Observed Broadleaf Fraction}

An approximate estimate of the broadleaf fraction in the real world was produced for the validation in section 5 . We used a simple procedure, because there are unavoidable limitations to the validation for which this estimate is used (discussed in section 5).

Our estimate of tropical tree cover is based on two steps: translation of the IGBP-DIScover land cover classifications (Loveland and Belward 1997) into the TRIFFID plant functional types and then upscaling to the HadCM3LC grid.

The mapping from the IGBP classification to broadleaf fraction (Table A1) was adapted from the mapping of Wilson and Henderson-Sellers (1985), who produced a mapping from 70 land cover classifications to fractional coverage of each of the TRIFFID plant functional types. The IGBP classification has only 17 land cover types. Therefore, for each of the 17 IGBP types, we selected the corresponding classification(s) from Wilson and Henderson-Sellers (1985). For each IGBP type we then took the average of the corresponding broadleaf fraction mappings from Wilson and Henderson-Sellers (1985).

TABLE A1. Mappings from IGBP land cover classification to TRIFFID broadleaf area fraction.

IGBP description

Evergreen needleleaf forest

Evergreen broadleaf forest

Deciduous needleleaf forest

Deciduous broadleaf forest

Mixed forest

Closed shrubs

Open shrubs

Woody savannah

Savannah

Grassland

Permanent wetland

Cropland

Urban

Crop-natural mosaic

Snow and ice

Barren

Water bodies
Broadleaf fraction

0.0

86

0.0

62

36

0.0

0.9

50

20

0.0

2.2

0.1

0.0

5.0

0.0

0.0

0.0 


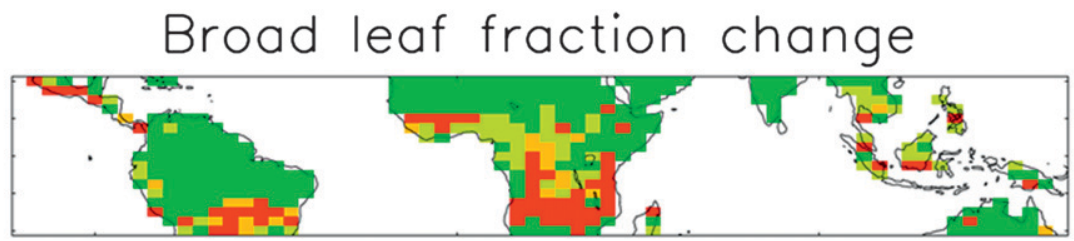

a)
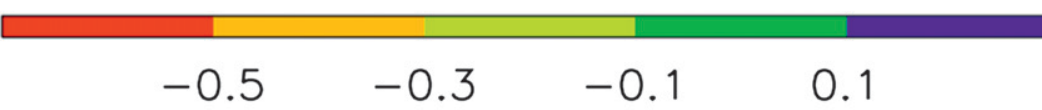

0.1

b)
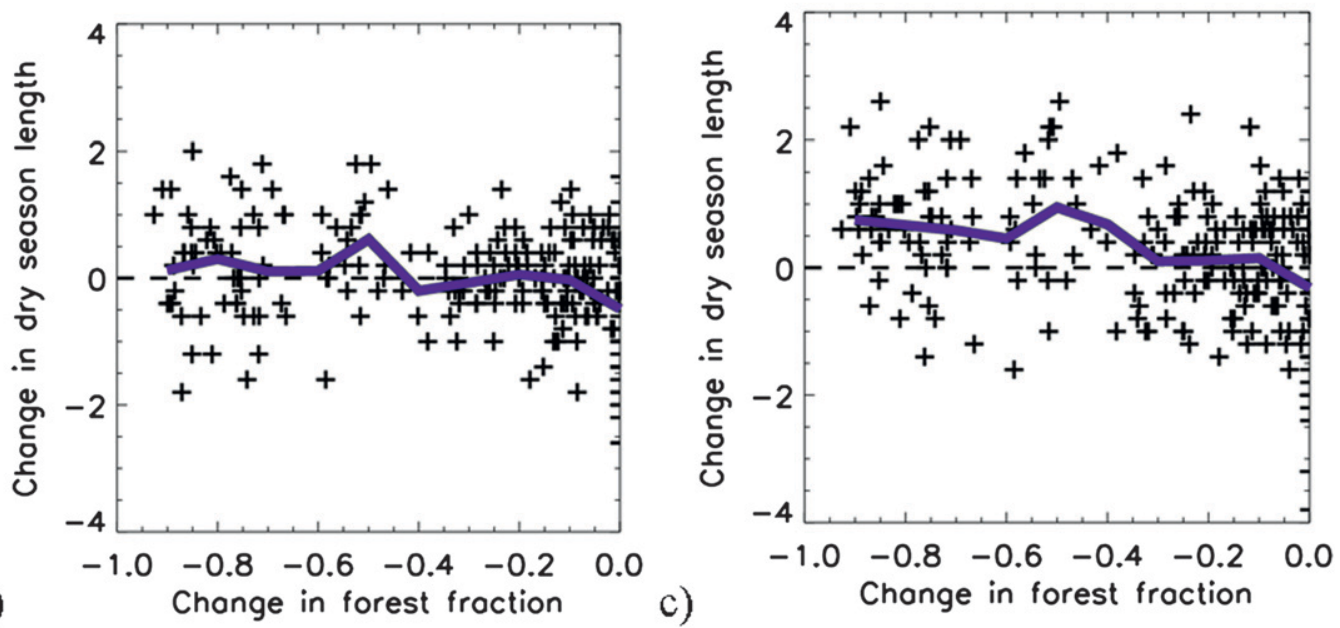

FIG. C1. Changes from the 2100s to the 2100s-lowVegCO2 experiment (see appendix C). (a) The change in forest fraction. (b) The $\Delta_{0}$ change in dry season length against the change in forest fraction. Each cross represents one location. Blue line is the binned average (for bins of width 0.1). (c) As in (b), but for the $\Delta_{1}$ change in dry season length.

Upscaling of the broadleaf fraction from the highresolution IGBP grid to each HadCM3LC grid cell was then done by taking the area-weighted average of the broadleaf fraction.

\section{APPENDIX B}

\section{Optimization Procedure}

We estimated the constants of the DSR function $\left[\alpha_{T}\right.$, $\alpha_{\mathrm{CO} 2}$, and $c$ in Eq. (1)] using a numerical optimization procedure. The aim of the optimization is to derive a DSR function that can identify the two bioclimatic zones of high and low forest cover seen in Fig. 2, for a wide range of climate- $\mathrm{CO}_{2}$ states.

The optimization was applied to a dataset comprising the forest fraction and the three climate drivers at each tropical land location from each of the five model experiments. This explores a wide range of states, spanning temperatures from $17^{\circ}$ to $40^{\circ} \mathrm{C}$, dry season lengths from 0.4 to 12 months, and $\mathrm{CO}_{2}$ concentrations from 390 to 1027 ppmv.

We estimated the constants in Eq. (1) by numerical maximization of the following quantity, denoted the bioclimatic zone difference: (broadleaf fraction averaged over locations with DSR $>0$ ) - (broadleaf fraction averaged over locations with DSR $<0$ ). This method tends to choose parameters such that the contour DSR = 0 lies along the boundary between the bioclimatic zones of high and low forest cover (Fig. 2).

The choice of numerical method to perform the optimization is a technical rather than scientific issue. Since computer time was not an issue, we used the following simple method. First, broad plausible ranges for $\alpha_{T}, \alpha_{\mathrm{CO} 2}$, and $c$ were established by inspection of Fig. 2. The range of each of the three constants was subdivided into a fine grid. The bioclimatic zone difference was calculated for all possible combinations of the 3 constants on the 3 grids. The combination of $\alpha_{T}, \alpha_{\mathrm{CO} 2}$, and $c$ giving the maximum bioclimatic zone difference was chosen as the optimal solution. Successively finer grids were chosen to ensure that the optimization was not sensitive to the nature of the grid.

\section{APPENDIX C}

\section{Estimation of the Influence of Forest Loss on Dry Season Length}

We estimate a typical magnitude for the influence of forest loss on dry season length in this model by comparing the 2100s and 2100s-lowVegCO2 experiments. 
The 2100s-lowVegCO2 was initialized from the end of the 2100 s experiment, and a form of artificial "deforestation" caused by reducing the $\mathrm{CO}_{2}$ experienced by the vegetation to year-2000 levels was used. We examine how the climate changes at each location as a result of this forest loss.

For this section, we average dry season length over the last $5 \mathrm{yr}$ of both the 2100s experiment and the 2100slowVegCO2 experiment. This measures the dry season length after the forest and climate have fully come into equilibrium with each other in each experiment. We also use the mean dry season length over years 10-14 of the 2100s-lowVegCO2 experiment. This indicates the dry season length before the forest has fully adjusted to the reduction in $\mathrm{CO}_{2}$. We measure two different changes in dry season length:

$$
\begin{aligned}
& \left.\Delta_{0} \text {, where (years } 10-14 \text { of } 2100 \mathrm{~s}-\mathrm{lowVegCO} 2\right)-(\text { last } \\
& 5 \mathrm{yr} \text { of } 2100 \mathrm{~s}) \text {, and } \\
& \Delta_{1} \text {, where (last } 5 \mathrm{yr} \text { of } 2100 \mathrm{~s}-\mathrm{low} V \text { egCO2) }- \text { (last } 5 \mathrm{yr} \\
& \text { of 2100s). }
\end{aligned}
$$

Here, $\Delta_{1}$ estimates the effects of forest loss on dry season length, and $\Delta_{0}$ is a control, giving an estimate of the internal variability in dry season length.

The broadleaf fraction is taken from the end of each experiment. Changes in forest fraction are expressed as differences between the two experiments: 2100slowVegCO2 and 2100s. Forest loss occurs over all tropical continents, especially over Africa (Fig. C1a).

Figure $\mathrm{C} 1 \mathrm{~b}$ plots the $\Delta_{0}$ change in dry season length against the change in forest fraction (by the end of 2100slowVegCO2), for each tropical land location. The scatter is quite high, due to the internal variability in dry season length. Figure $\mathrm{Cl}$ c is similar to Fig. $\mathrm{C} 1 \mathrm{~b}$, but showing the $\Delta_{1}$ change in dry season length (including the full effects of forest loss). The scatter is similar to Fig. C1b, but now regions with large forest loss tend toward small increases in dry season length. Where the forest fraction loss is greater than about 0.4 , we find a mean increase in dry season length of around 0.7 months. This magnitude of change is small compared to the spatial variation seen in Fig. 2 (the dry season length varies from 0.5 to 12 months in the $2005 \mathrm{~s}$ simulation).

\section{REFERENCES}

Arora, V. K., and G. J. Boer, 2006: Simulating competition and coexistence between plant functional types in a dynamic vegetation model. Earth Interactions, 2. [Available online at http://EarthInteractions.org.]

Baker, I. T., L. Prihodko, A. S. Denning, M. Goulden, S. Miller, and H. R. da Rocha, 2008: Seasonal drought stress in the Amazon: Reconciling models and observations. J. Geophys. Res., 113, G00B01, doi:10.1029/2007JG000644.
Betts, R. A., P. M. Cox, M. Collins, P. P. Harris, C. Huntingford, and C. D. Jones, 2004: The role of ecosystem-atmosphere interactions in simulated Amazonian precipitation decrease and forest dieback under global climate warming. Theor. Appl. Climatol., 78, 157-175.

Cowling, S. A., P. M. Cox, R. A. Betts, V. J. Ettwein, C. D. Jones, M. A. Maslin, and S. A. Spall, 2004: Contrasting simulated past and future responses of the Amazonian forest to atmospheric change. Philos. Trans. Roy. Soc., 359B, 539-547.

Cox, P. M., 2001: Description of the TRIFFID dynamic global vegetation model. Met Office Tech. Note 24, 17 pp.

, R. A. Betts, C. D. Jones, S. A. Spall, and I. J. Totterdell, 2000: Acceleration of global warming due to carbon-cycle feedbacks in a coupled climate model. Nature, 408, 184-187.

,-- , M. Collins, P. P. Harris, C. Huntingford, and C. D. Jones, 2004: Amazonian forest dieback under climate-carbon cycle projections for the 21st century. Theor. Appl. Climatol., 78, $137-156$.

_ due to decreasing aerosol pollution. Nature, 453, 212-215.

Cramer, W., and Coauthors, 2001: Global response to terrestrial ecosystem structure and function to $\mathrm{CO}_{2}$ and climate change: Results from six dynamic global vegetation models. Global Change Biol., 7, 357-373.

Crucifix, M., R. A. Betts, and C. D. Hewitt, 2005: Pre-industrialpotential and Last Glacial Maximum global vegetation simulated with a coupled climate-biosphere model: Diagnosis of bioclimatic relationships. Global Planet. Change, 45, 295-312.

Essery, R. L. H., M. J. Best, R. A. Betts, P. M. Cox, and C. M. Taylor, 2003: Explicit representation of subgrid heterogeneity in a GCM land-surface scheme. J. Hydrometeor., 4, 530-543.

Field, C. B., R. B. Jackson, and H. A. Mooney, 2008: Stomatal responses to increased $\mathrm{CO}_{2}$-Implications from the plant to the global scale. Plant Cell Environ., 18, 1214-1225.

Friedlingstein, P., and Coauthors, 2006: Climate-carbon cycle feedback analysis: Results from the $\mathrm{C}^{4} \mathrm{MIP}$ model intercomparison. J. Climate, 19, 3337-3353.

Galbraith, D., P. E. Levy, S. Sitch, C. Huntingford, M. Williams, and P. Meir, 2010: Multiple mechanisms of Amazonian forest biomass losses in three dynamic global vegetation models under climate change. New Phytol., 187, 647-665.

Good, P., J. A. Lowe, M. Collins, and W. Moufouma-Okia, 2008: An objective tropical Atlantic sea surface temperature gradient index for studies of south Amazon dry-season climate variability and change. Philos. Trans. Roy. Soc., 363B, 17611766.

Harris, P. P., C. Huntingford, and P. M. Cox, 2008: Amazon basin climate under global warming: The role of the sea surface temperature. Philos. Trans. Roy. Soc., 363B, 1753-1759.

Holdridge, L. R., 1947: Determination of world plant formations from simple climatic data. Science, 105, 367-368.

Jones, C., J. Lowe, S. Liddicoat, and R. Betts, 2009: Committed terrestrial ecosystem changes due to climate change. Nat. Geosci., 2, 484-487.

Keeling, R. F., S. C. Piper, A. F. Bollenbacher, and J. S. Walker, cited 2009: Atmospheric $\mathrm{CO}_{2}$ records from sites in the $\mathrm{SIO}$ air sampling network. Trends: A Compendium of Data on Global Change, Carbon Dioxide Information Analysis Center, Oak Ridge National Laboratory, doi:10.3334/CDIAC/atg.035.

Köppen, W., 1936: Das feographische system der klimate. Handbuch der Klimatoligie, Vol. I, Part C, W. Köppen and R. Geiger, Eds., Gebruder Borntraeger, 1-44. 
Lapola, D. M., M. D. Oyama, and C. A. Nobre, 2009: Exploring the range of climate biome projections for tropical South America: The role of $\mathrm{CO}_{2}$ fertilization and seasonality. Global Biogeochem. Cycles, 23, GB3003, doi:10.1029/2008GB003357.

Lenton, T. M., H. Held, E. Kriegler, J. W. Hall, W. Lucht, S. Rahmstorf, and H. J. Schellnhuber, 2008: Tipping elements in the earth's climate system. Proc. Natl. Acad. Sci. USA, 105, 1786-1793.

Lewis, S. L., and Coauthors, 2009: Increasing carbon storage in intact African tropical forests. Nature, 457, 1003-U3.

Loveland, T. R., and A. S. Belward, 1997: The International Geosphere Biosphere Programme Data and Information System global land cover data set. Acta Astronaut., 41, 681-689.

Malhi, Y., and Coauthors, 2009: Exploring the likelihood and mechanism of a climate-change-induced dieback of the Amazon rainforest. Proc. Natl. Acad. Sci. USA, 106, 20 610-20 615.

Marengo, J. A., and Coauthors, 2008: The drought of Amazonia in 2005. J. Climate, 21, 495-516.

Meehl, G. A., and Coauthors, 2007: Global climate projections. Climate Change 2007: The Physical Science Basis, S. Solomon et al., Eds., Cambridge University Press, 747-845.

Mercado, L. M., N. Bellouin, S. Sitch, O. Boucher, C. Huntingford, M. Wild, and P. M. Cox, 2009: Impact of changes in diffuse radiation on the global land carbon sink. Nature, 458, 1014 1017, doi:10.1038/nature07949.

Mitchell, T. D., and P. D. Jones, 2005: An improved method of constructing a database of monthly climate observations and associated high-resolution grids. Int. J. Climatol., 25, 693-712.

Nakicenovic, N., and Coauthors, 2000: Emissions Scenarios. Cambridge University Press, $570 \mathrm{pp}$.

Nemani, R. R., and Coauthors, 2003: Climate-driven increases in global terrestrial net primary production from 1982 to 1999. Science, 300, 1560-1563.

Norby, R. J., and Coauthors, 2005: Forest response to elevated $\mathrm{CO}_{2}$ is conserved across a broad range of productivity. Proc. Natl. Acad. Sci. USA, 102, 18 052-18 056.

Orr, J. C., and Coauthors, 2005: Anthropogenic ocean acidification over the twenty-first century and its impact on calcifying organisms. Nature, 437, 681-686.
Phillips, O. L., and Coauthors, 2009: Drought sensitivity of the Amazon rainforest. Science, 323, 1344-1347.

Prentice, K. C., and I. Y. Fung, 1990: The sensitivity of terrestrial carbon storage to climate change. Nature, 346, 48-51.

Salazar, L. F., C. A. Nobre, and M. D. Oyama, 2007: Climate change consequences on the biome distribution in tropical South America. Geophys. Res. Lett., 34, L09708, doi:10.1029/ 2007 GL029695.

Saleska, S. R., K. Didan, A. R. Huete, and H. R. da Rocha, 2007: Amazon forests green-up during 2005 drought. Science, 318, 612, doi:10.1126/science.1146663.

Scholze, M., W. Knorr, N. W. Arnell, and I. C. Prentice, 2006: A climate-change risk analysis for world ecosystems. Proc. Natl. Acad. Sci. USA, 103, 13 116-13 120.

Sitch, S., and Coauthors, 2008: Evaluation of the terrestrial carbon cycle, future plant geography and climate-carbon cycle feedbacks using five dynamic global vegetation models (DGVMs). Global Change Biol., 14, 2015-2039.

Smith, T. M., and H. H. Shugart, 1993: The transient-response of terrestrial carbon storage to a perturbed climate. Nature, $\mathbf{3 6 1}$, 523-526.

_ R. Reemans, and H. H. Shugart, 1992: Sensitivity of terrestrial carbon storage to $\mathrm{CO}_{2}$-induced climate change: Comparison of four scenarios based on general circulation models. Climatic Change, 21, 367-384.

ter Steege, H., and Coauthors, 2006: Continental-scale patterns of canopy tree composition and function across Amazonia. $\mathrm{Na}$ ture, 443, 444-447.

Thornton, P. E., and Coauthors, 2009: Carbon-nitrogen interactions regulate climate-carbon cycle feedbacks: Results from an atmosphere-ocean general circulation model. Biogeosciences, 6, 2099-2120.

White, A., M. G. R. Cannell, and A. D. Friend, 1999: Climate change impacts on ecosystems and the terrestrial carbon sink: A new assessment. Global Environ. Change, 9 (Suppl.), S21-S30.

Wilson, M. F., and A. Henderson-Sellers, 1985: A global archive of land cover and soils data for use in general-circulation climate models. J. Climatol., 5, 119-143. 